\title{
Bulanık veri zarflama analizi ile beton pompası seçimi
}

\author{
Volkan ARSLAN*,1, Serdar ULUBEYLI' ${ }^{1}$, \\ ${ }^{1}$ Bülent Ecevit Üniversitesi, İnşaat Mühendisliği Bölümü, Zonguldak
}

Makale Gönderme Tarihi: 02.11.2015 Makale Kabul Tarihi: 25.03.2016

\section{$\ddot{\mathbf{O z}}$}

Bu çalışmanın amacı, inşaat sektöründeki makine seçimleri problemine, beton pompası açısından yaklaşmak ve beton pompası üreticileri ve kullanıcılarına, üretim ve satın alma süreçlerinde yardımcı olabilecek bir yöntem ortaya koymaktır. Bu kapsamda, çok ölçütlü karar verme problemlerini çözmek için kullanılan yöntemlerden biri olan veri zarflama analizi, elde edilen verilerin bazılarının bulanık sayllar olmaları nedeniyle, bulanı veri zarflama analizi (BVZA) olarak kullanılmıştır. Hesaplamalarda hem bulanık ve hem de normal sayıları aynı anda işleyebilmek için Madea ve diğerleri (1998) tarafindan geliştirilen ve Saati ve diğerleri (2002) tarafindan iyileştirilen a-kesim kümeleri yaklaşımından faydalanılmıştır. Çalışma kapsamında, Türkiye'de faaliyet gösteren üç farklı beton pompası üreticisi tarafindan üretilen aynı tipteki birer adet beton pompasinın özellikleri ve beton pompası kullanıcısı 70 adet firmanın makine sorumluları ile yapılan görüşmelerden elde edilen veriler kullanilarak, söz konusu beton pompalarının etkinlikleri hesaplanmıştır. Bu etkinlik hesaplaması sırasında Charnes-Cooper-Rhodes yöntemi ile elde edilen eşitlikler kullanılmıştır.

Sonuç olarak, değerlendirmeye alınan üç farklı beton pompası içerisinden B3 kodlu beton pompasi, etkinlik değeri en yüksek olan seçenek olarak belirlenmiştir. Bu çalışma sonucunda elde edilen bulguların; beton pompası üreticilerinin pazardaki durumlarını görmelerine, ürünlerini geliştirerek rekabet güçlerini artırmalarına ve potansiyel alıcı ve kullanıcıların en uygun ürünü seçmelerine yardımcı olabilecekleri düşünülmektedir. Ayrıca BVZA'nın, çok ölçütlü karar verme problemlerinde karşılaşılan farklı tür ve birimlerdeki verilerin, mevcut kısttlarla birlikte değerlendirilmesinde kullanılabilecek oldukça faydalı bir yöntem olduğu ortaya konulmuştur. Bu yöntem ile bir veya birden çok parametre hedeflenerek hesaplamalar yapılabilmekte ve karar verme sürecinde avantaj sağlanabilmektedir.

Anahtar Kelimeler: Beton pompası, BVZA, Çok ölçütlü karar verme, İş̧aat makineleri

\footnotetext{
${ }^{*}$ Yazışmaların yapılacağı yazar: Volkan ARSLAN. volkanarslan@beun.edu.tr
} 


\section{Giriş}

Karar verme veya problem çözme, hedefe ulaşmak için en uygun seçenek veya seçenekleri seçme süreci olarak tanımlanabilir. İnşaat sektöründeki karar verme süreci ise inşaat projelerinin yapısına bağlı olarak oldukça karmaşık ve zaman alan bir süreçtir. İnşaat sektöründeki projelerin ve bununla ilgili masrafların büyüklüğü göz önüne alındığında, uygun olmayan seçimler büyük miktarda para ve zaman kaybına yol açabilmektedir. İnşaat projelerindeki en zor problemlerden biri, özellikle kullanılacak teknoloji ve malzemelerin seçiminde objektif kararlar alabilmektir. $\mathrm{Bu}$ açıdan, genel anlamda inşaat makineleri seçimi, özel olarak ise beton pompası seçimi, çok ölçütlü bir karar verme problemi olarak ele alınabilir (Ksiazek vd., 2014).

Literatürde daha önce, Tam ve diğerleri (2004) tarafindan SIR yöntemi ve Ulubeyli ve Kazaz (2009) tarafından ise ELECTRE III yöntemi ile beton pompası seçimi üzerine çalışmalar yapılmıştır. $\mathrm{Bu}$ çalışmada kullanılan Veri Zarflama Analizi (VZA) ise bahsi geçen bu iki yönteme göre belirli üstünlüklere sahiptir. Öncelikle VZA, çoklu göstergeler içeren bir değerlendirme mekanizması kurmak ve bu göstergelerin ağırlıklarını tarafsız bir şekilde belirlemek için oldukça iyi bir yöntem olarak değerlendirilebilir (Wang vd., 2009). VZA; her bir alternatif için benzerlerine göre etkinlik değerleri üreten ve parametrik olmayan bir doğrusal programlama yaklaşımı olup, seçeneklerin mevcut diğer seçeneklere bağlı etkinliklerini hesaplamayı sağlamaktadır. Ayrıca VZA, her karar verme birimini (KVB) değerlendirerek, çoklu girdi ve çoklu çıktı durumları için kapsamlı bağıl etkinlik analizi yapılmasını ve karar verme yöntemlerinin matematiksel doğrusal programlama kullanan bu zarflama düzeyine bağlı performanslarının ölçülmesini sağlamaktadır. VZA'nın diğer yöntemlerden ayrıldığı nokta; bu yöntemin, belirli bir performansta kullanılmış kaynakları, bu performans ile ilgili başarı seviyesine bağlamasıdır (El-Mashaleh vd., 2010).
Çok ölçütlü karar verme problemlerinde nitelik değerleri ve bağıl ağırlıklar genellikle bulanık sayılardan oluşmaktadır (Torfi vd., 2010). Bulanık küme, devam eden üyelik derecelerine sahip objeler kümesidir (Zadeh, 1965). Bir bulanık sayı, 0 ile 1 aralığından oluşan bir dışbükey kümedir ve en çok kullanılan bulanık sayılar üçgen ve ikizkenar yamuk şeklinde olanlardır (Taylan vd., 2014). Literatürde bulanık veriler ile işlem yapabilen birçok bulanık veri zarflama analizi (BVZA) çalışması bulunmaktadır. $\mathrm{Bu}$ çalışmada, Maeda ve diğerleri (1998) tarafından geliştirilen ve Saati ve diğerleri (2002) tarafından iyileştirilen $\alpha$ kesim kümeleri yaklaşımı, beton pompası seçimi için karar vermede kullanılmıştır.

Sonuç olarak, bu çalışma sonucunda elde edilen bulguların; beton pompası üreticilerinin pazardaki kendi durumlarını görmelerine, ürünlerini geliştirerek rekabet güçlerini artırmalarına ve potansiyel alıcı ve kullanıcıların ise en uygun ürünü seçmelerine yardımc1 olabilecekleri düşünülmektedir.

\section{VZA}

VZA; bir grup KVB’nin, çoklu kaynak (girdi) kullanarak çoklu sonuç (çıktı) üretmesinde karşılaştırmalı etkinlik ile değerlendirme yapan ve parametrik olmayan doğrusal programlama yaklaşımlarından biridir (Chang ve Lee, 2012). $\mathrm{Bu}$ yöntem, homojen KVB'lerin bağıl etkinliğini, üretim fonksiyonlarını bilmeden, sadece girdi ve çıktı verilerini kullanarak hesaplayabilmektedir (Zhou vd., 2012). VZA, çoklu girdi ve çıktı durumları için her KVB'yi değerlendirerek ve her birimin etkin sınır olan zarflama yüzeyine ilişkin performansını ölçerek, bağıl etkinliğin kapsamlı bir analizini ortaya koymaktadır. $\mathrm{Bu}$ sınırın üzerinde yer alan birimler VZA terminolojisinde etkin olarak isimlendirilirken, diğerleri yetersiz olarak belirlenmekte ve analizler bunların bağıl etkinliklerinin ölçümünü sağlamaktadır (ElMashaleh vd., 2010). Cook ve Green'e (2000) göre VZA, çok boyutlu bir alternatifler kümesini tanımlamakta ve şu sonuçlara ulaşmayı hedeflemektedir: (i) en iyi alternatifi 
belirlemek, (ii) alternatifleri sıralamak ve (iii) daha iyi olan alternatiflerin gözden geçirilmesi için bir liste oluşturmak. Ayrıca, Coelli ve diğerleri (1998) ve Cooper ve diğerleri (2000) VZA'nın popülerliğini şu üç özelliğine borçlu olduğunu belirtmektedirler: (i) doğrusal programlama kullanarak, çoklu girdi ve çoklu çıktıları birleştirmek kabiliyeti, (ii) varsayımlarının olmaması ve bir birimin performansını, o birimin ağırlığına göre en iyileyen ve diğer birimlerin, önündekilerin sınırlarını ihlal etmesine izin vermeyen bir ağırlıklar kümesi sağlaması ve (iii) ölçüm birimlerinin farklı girdi ve çıktılar için uyumlu olmasına gerek olmaması. İnşaat sektöründe yapılan akademik çalışmaların çok azında VZA yöntemi kullanılmıștır. Bunlardan bazıları; müteahhit seçim süreci (El-Mashaleh, 2010), firmaların iş sağlığı ve güvenliği performanslarının ölçümü (El-Mashaleh vd., 2010), köprü bakımı süreçlerinin etkinliği (Ozbek vd., 2010), dış cephe boyalarının ekoetkinlikleri (Tatari ve Küçükvar, 2011) ve sicak asfalt karışımlarının karşılaştııılması (Li vd., 2013) şeklinde sayılabilir.

\section{BVZA}

VZA kullanılırken ortaya çıkabilecek kısıtlamalardan biri, girdi ve çıtıtı verilerini elde etmek için eksiksiz ölçümler yapılması gerekliliğidir. Ancak, ihtiyaç duyulan girdi ve çıktı değerleri, bazen kesin olmayan veya muğlak değerler olabilmektedir. Kesin olmayan veriler ile etkinlik hesabı yapmak oldukça zordur. Ayrıca, etkinlik analizleri için kullanılabilecek mevcut veriler genellikle nitel ve dilsel ifadelerle belirtilen şekillerde olmaktadırlar (Lertworasirikul vd., 2003). Bu gibi belirsiz, nitel veya dilsel ifadelere bulanık ifadeler denilmektedir. Bulanık çıkarım, verilen bir girdi değişkenleri kümesinden, bulanık kurallar kümesine dayanarak, bir çıktı elde etme sürecidir. (Toprak ve Savc1, 2007; Toprak ve Cığızoğlu, 2008; Toprak vd., 2009; Toprak, 2009; Akkoyun ve Toprak, 2012; Toprak vd., 2014).
KVB'leri değerlendirmek için kullanılan BVZA yaklaşımları dört kategoride sınıflandırılmaktadırlar: (i) tolerans yaklaşımı (Sengupta, 1992), (ii) Maeda ve diğerleri (1998) tarafından geliştirilen ve Kao ve Liu (2000) ile Saati ve diğerleri (2002) tarafından iyileştirilen $\alpha$-kesim temelli yaklaşım, (iii) bulanık derecelendirme yaklaşımı (Guo ve Tanaka, 2001) ve (iv) durulaştırma yaklaşımı (Lertworasirikul vd., 2003). $\alpha$-kesim temelli yaklaşımda BVZA modeli, $\alpha$-kesimleri kavramı kullanılarak parametrik programlamaya dönüştürülmektedir. $\mathrm{Bu}$ yaklaşımın amacı, belirtilen seviyelerde BVZA modelini çözerek, daha sonra bulanık etkinlik değerini oluşturmak için kullanılan ve değerlendirme altında olan KVB'ye ait bulanık etkinlik değerine karşılık gelen $\alpha$-kesimlerini elde edilebilmektir (Zhou vd., 2012).

\section{Charnes-Cooper-Rhodes (CCR) VZA modeli}

$\mathrm{Bu}$ çalışmada CCR modeli kullanılmıştır. $\mathrm{Bu}$ modelin matematiksel ifadesi aşağıdaki eşitliklerde gösterilmiştir. Amaç fonksiyonu olan (1) numaralı eşitlik, KVBo etkinliğini en iyilemekte ve bu çıktıların toplamının en iyilenmesi sırasında, girdilerinin 1'e eşitlenmeye zorlanması (2) numaralı eşitlik ile gerçekleşmektedir. (3) numaralı eşitliğin anlamı, tüm KVB'lerin etkinlik değerlerinin 1'den küçük veya eşit olması gerektiğidir. Buna göre, tüm KVB'ler ya etkinlik sınırı üzerindedir ya da altındadır ve bu etkinlik değerleri 0 ile 1 arasında değişmektedir (El-Mashaleh vd., 2010).

Amaç fonksiyonu:

$e_{o}-\max \sum_{r=1}^{s} u_{r} y_{r o}$

Kisitlar:

$\sum_{i=1}^{m} v_{i} x_{i o}=1$

$\sum_{r=1}^{s} u_{r} y_{r j} \leq \sum_{i=1}^{m} v_{i} x_{i j}$

$v_{i}, u_{r} \geq \varepsilon, \quad r=1,2 . ., s \quad i=1,2, . ., m \quad j=1,2, . ., n$

$\varepsilon=10^{-6}$ 
Bu eşitliklerde,

eo : Değerlendirme altında olan (o.) KVB'nin etkinlik ölçüm değeri $(j=1,2, \ldots, n)$

$n \quad:$ KVB sayıs $j=1,2, \ldots, n$

$s \quad:$ Ç1ktı sayısı $r=1,2, \ldots, s$

$m \quad$ : Girdi sayıs $1 i=1,2, \ldots, m$

ur : o. KVB tarafından r. çıktıya verilen ağırlık değeri

$v i \quad$ : o. KVB tarafindan i. girdiye verilen ağırlık değeri

yro : o. KVB'nin elde ettiği $r$. çıktı miktarı

xio : o. KVB'nin kullandığ 1 . girdi miktarı

$y r j \quad: \mathrm{j}$. KVB'nin elde ettiği $r$. çıktı miktarı

$x_{i j} \quad$ j. KVB'nin kullandığ $i$ girdi miktarıdır.

Sonuç olarak, bir alternatifin etkin sayılması için etkinlik değerinin 1 olması gerekmektedir. $\mathrm{Bu}$ durumda, söz konusu alternatifin etkinlik sınırı üzerinde olduğu anlaşılmakta ve diğer alternatiflerle karşılaştırıldığında bu alternatifin, girdileri çıktılara daha etkin bir biçimde dönüştürdüğü söylenebilmektedir.

\section{Üçen Üyelik Fonksiyonu}

Genel olarak bulanık kümeler birbiri ile kesişmekte ve kümelerin üyelik fonksiyonu şekilleri girdi ve çıtıların etkilerine göre belirlenmektedir (Aluclu vd, 2008). Bu çalışmada, bulanık sayıların üyelik derecelerini belirlemek için üçgen üyelik fonksiyonu kullanılmıştır. Şekil 1'de örnek bir üçgen üyelik fonksiyonu gösterilmiştir. Burada $\mu \tilde{\mathrm{A}}$ bulanık bir sayının üyelik fonksiyonunu, 1 alt sınırını, $m$ modal değerini ve $u$ üst sınırını temsil etmektedir.

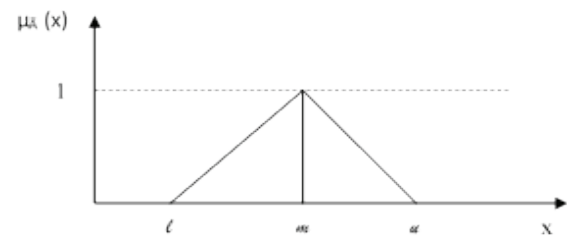

Şekil 1. Üçgen üyelik fonksiyonu

Ã, R'de bir bulanık sayı olsun. Eğer bu sayı üçgen üyelik fonksiyonuna sahip ise sayının üyelik fonksiyonu $\mathrm{x} \in \tilde{\mathrm{A}}, \mu_{\tilde{\mathrm{A}}}(\mathrm{x}): \mathrm{R} \rightarrow[0,1]$ olup, üyelik derecesi aşağıdaki şekilde hesaplanmaktadır.

$$
\mu_{\tilde{A}}(\mathrm{x})=\left\{\begin{array}{lc}
(\mathrm{x}-l) /(m-l), & l \leq \mathrm{x} \leq m \\
(u-\mathrm{x}) /(u-m), & m \leq \mathrm{x} \leq u \\
0, & \text { diğer durumlarda }
\end{array}\right.
$$

Üçgen üyelik fonksiyonuna sahip bulanık bir sayı $\tilde{\mathrm{A}}=(l, m, u)$ şeklinde gösterilmektedir.

\section{Bulanık CCR modeli}

Çoklu girdi ve çoklu çıktı verilerine sahip olan KVB'lerin değerlendirilmesi sürecinde, girdi ve çıktıların ayrı ayrı bir araya getirilerek etkinlik olarak bir oran oluşturulması için bir ağırlık kümesinin belirlenmesi gerekmektedir. Bu süreç üç aşamada gerçekleştirilmektedir. İlk aşamada, her faktör için doğrusal programlama problemi çözerek, verilerin alabilecekleri ağırlıkların üst sınır değeri; ikinci aşamada, tüm KVB'ler için bir ortak ağırlık kümesi; son aşamada ise ilk iki aşamadan elde edilen sonuçlar kullanılarak KVB'lerin etkinlik değerleri hesaplanmaktadır (Oruç, 2008).

-1. Aşama: Bulanık girdi-çıktı verilerinin alabileceği ağırlıkların üst sınırlarının belirlenmesi için aşağıdaki modeller tanımlanabilir.

p. çıktının üst sınırı için amaç fonksiyonu:

$\max u_{p}$

Kisitlar:

$\sum_{i=1}^{m} \overline{x_{i j}} \leq 1$

$\sum_{r=1}^{s} \overline{y_{r j}}-\sum_{i=1}^{m} \overline{x_{i j}} \leq 0$

$v_{i}\left[\alpha x_{i j}^{m}+(1-\alpha) x_{i j}^{l}\right] \leq x_{i j} \leq v_{i}\left[\alpha x_{i j}^{m}+(1-\alpha) x_{i j}^{u}\right]$

$u_{r}\left[\alpha y_{r j}^{m}+(1-\alpha) y_{r j}^{l}\right\rfloor \leq y_{r j} \leq u_{r}\left[\alpha y_{r j}^{m}+(1-\alpha) y_{r j}^{u}\right\rfloor$

$v_{i}, u_{r} \geq \varepsilon, \quad r=1,2 . ., s \quad i=1,2, . ., m \quad j=1,2, . ., n$

$\varepsilon=10^{-6}$ 
t. girdinin üst sınırı için amaç fonksiyonu:

$\max v_{t}$

Kisitlar:

$\sum_{i=1}^{m} \overline{x_{i j}} \leq 1$

$\sum_{r=1}^{s} \overline{y_{r j}}-\sum_{i=1}^{m} \overline{x_{i j}} \leq 0$

$v_{i}\left[\alpha x_{i j}^{m}+(1-\alpha) x_{i j}^{l}\right] \leq x_{i j} \leq v_{i}\left[\alpha x_{i j}^{m}+(1-\alpha) x_{i j}^{u}\right]$

$u_{r}\left[\alpha y_{r j}^{m}+(1-\alpha) y_{r j}^{l}\right] \leq y_{r j} \leq u_{r}\left[\alpha y_{r j}^{m}+(1-\alpha) y_{r j}^{u}\right]$

$v_{i}, u_{r} \geq \varepsilon, \quad r=1,2 . ., s \quad i=1,2, . ., m \quad j=1,2, . ., n$

$\varepsilon=10^{-6}$

Önerilen model, amaç fonksiyonunu maksimize etmek için herhangi bir $\alpha$ kesiminde, $\overline{y_{r o}}=u_{r}\left(y_{r o}\right)_{\alpha}^{u}, \overline{x_{i o}}=v_{i}\left(x_{i o}\right)_{\alpha}^{l}$

ve

$\overline{y_{r j}}=u_{r}\left(y_{r j}\right)_{\alpha}^{u}, \overline{x_{i j}}=v_{i}\left(x_{i j}\right)_{\alpha}^{l}, j \neq 0$

değerine ulaşılmasına izin vermektedir.

-2. Aşama: Tüm KVB'lerin ağırlık değerlerinde aynı oranda sapma olduğu kabul edilerek ortak ağırlık kümesi oluşturulmaktadır. Bu amaçla, üçgen üyelik fonksiyonuna sahip bulanık veriler ve (17) - (23) arasındaki eşitlikler kullanılarak hesaplamalar yapılmaktadır (Oruç, 2008).

Amaç fonksiyonu:

$\max \varphi$

Kisitlar:

$\sum_{r=1}^{s} \overline{y_{r j}}-\sum_{i=1}^{m} \overline{x_{i j}} \leq 0$

$v_{i}\left[\alpha x_{i j}^{m}+(1-\alpha) x_{i j}^{l}\right] \leq x_{i j} \leq v_{i}\left[\alpha x_{i j}^{m}+(1-\alpha) x_{i j}^{u}\right]$

$u_{r}\left[\alpha y_{r j}^{m}+(1-\alpha) y_{r j}^{l}\right] \leq y_{r j} \leq u_{r}\left[\alpha y_{r j}^{m}+(1-\alpha) y_{r j}^{l}\right]$

$\varepsilon+\varphi\left(U_{r}-\varepsilon\right) \leq u_{r} \leq(1-\varphi)\left(U_{r}-\varepsilon\right)$

$\varepsilon+\varphi\left(V_{i}-\varepsilon\right) \leq v_{i} \leq(1-\varphi)\left(V_{i}-\varepsilon\right)$ $v_{i}, u_{r} \geq \varepsilon, \quad r=1,2 . ., s \quad i=1,2, . ., m \quad j=1,2, . ., n$

$\varepsilon=10^{-6}$

Burada,

$U_{r} \quad$ : Bir önceki modelle elde edilen $\mathrm{r}$. çıktının üst sınırı $(r=1,2, \ldots, s)$

$V_{i} \quad$ : Bir önceki modelle elde edilen i. girdinin üst sınırı $(i=1,2, \ldots, m)$

$\varphi \quad:$ Ağırlıklardaki sapma oranıdır.

-3. Aşama: 2. aşamada elde edilmiş olan ağırlıklar $\mathrm{u}_{\mathrm{r}}{ }^{*}$ ve $\mathrm{v}_{\mathrm{i}}{ }^{*}$ olarak adlandırıldığında, herhangi bir KVB için etkinlik değeri (24) numaralı eşitlik ile hesaplanmaktadır.

$\left(\tilde{e}_{o}\right)_{\alpha}=\frac{\sum_{r=1}^{s} u_{r}^{*} \tilde{y}_{r o}}{\sum_{i=1}^{m} v_{i}^{*} \tilde{x}_{i o}}$

(24) eşitliği ile hesaplanan etkinlik değerinin alt ve üst sınırları ile orta noktası, üçgen üyelik fonksiyonunun bölme işlemi özelliği kullanılarak (25), (26), (27) ve (28) numaraları eşitlikleri ile aşağıdaki şekilde hesaplanmaktadır:

$\left(\widetilde{e}_{j}\right)_{\alpha}=\left(e_{j}^{l}, e_{j}^{m}, e_{j}^{u}\right)_{\alpha}$

ise,

$\left(e_{o}^{m}\right)_{\alpha}=\frac{\sum_{r=1}^{s} u_{r}^{*} \tilde{y}_{r o}^{m}}{\sum_{i=1}^{m} v_{i}^{*} \tilde{x}_{i o}^{m}}$

$\left(e_{o}^{l}\right)_{\alpha}=\left(e_{o}^{m}\right)_{\alpha}-\frac{\sum_{r=1}^{s} u_{r}^{*} y_{r o}^{m} \sum_{i=1}^{m} v_{i}^{*}\left(x_{i o}^{u}-x_{i o}^{m}\right)+\sum_{r=1}^{s} u_{r}^{*}\left(y_{r o}^{m}-y_{r o}^{l}\right) \sum_{i=1}^{m} v_{i}^{*} x_{i o}^{m}}{\left(\sum_{i=1}^{m} v_{i}^{*} x_{i o}^{m}\right)^{2}}$

$\left(e_{o}^{u}\right)_{\alpha}=\left(e_{o}^{m}\right)_{\alpha}+\frac{\sum_{r=1}^{s} u_{r}^{*} y_{r o}^{m} \sum_{i=1}^{m} v_{i}^{*}\left(x_{i o}^{m}-x_{i o}^{l}\right)+\sum_{r=1}^{s} u_{r}^{*}\left(y_{r o}^{u}-y_{r o}^{m}\right) \sum_{i=1}^{m} v_{i}^{*} x_{i o}^{m}}{\left(\sum_{i=1}^{m} v_{i}^{*} x_{i o}^{m}\right)^{m}}$

Etkinlik değeri hesaplanırken bulanık sayılarda aritmetik işlem uygulandığı için herhangi bir KVB'nin etkinlik değeri 1'den büyük ya da tüm KVB'lerin etkinlik değeri 1'den küçük çıkabilmektedir. Böyle durumlarda

(29) 
numaraları eşitlik ile hesaplanan ağırlıklar $U_{r}^{*}$ ve $V_{i}^{*}$ yeni ortak ağırlı kümesini oluşturmaktadırlar. Bu yeni ortak ağırlık kümesi belirlendikten sonra etkinlik değerleri tekrar hesaplanmaktadır (Saati ve Memariani, 2005).

$$
U_{r}^{*}=\frac{u_{r}^{*}}{e_{\max }}, V_{i}^{*}=v_{i}^{*}, e_{\max }=\max _{1 \leq j \leq m}\left\{e_{j}^{u}\right\}
$$

\section{Durum analizi: Beton pompası seçimi problemi}

Bu çalışmada, Türkiye'de faaliyet gösteren üç farklı beton pompası üreticisi tarafindan üretilen aynı tipteki birer adet beton pompası, çok ölçütlü karar verme problemi kapsamında, etkinlik değerlerine göre karşılaştırılmışlardır. $\mathrm{Bu}$ amaçla, söz konusu beton pompalarına ait pompalama hızı, günlük işletme maliyeti ve satış fiyatı olmak üzere üç adet nicel; teknik servis ve ikinci el firsatları olmak üzere de iki adet nitel ölçüt ele alınmıştır. Nitel ölçütlere ait verilere, Türkiye'de faaliyet gösteren 70 adet hazır beton tedarikçisi firmanın makine park1 yöneticileri ile yüz yüze yapılan anketler aracılığıyla ulaşılmış olup, 100 üzerinden notlar verilmiş ve modelde bunların aritmetik ortalamaları kullanılmıștır. Söz konusu anket iki bölümden oluşmaktadır. İlk bölümde, anket yapılan kişilerden beton pompası seçerken dikkat ettikleri ölçütleri tanımlamaları istenmiştir. İkinci bölümde ise mevcut makinelerin kullanıcılarının memnuniyet dereceleri ve tüm ölçütlerin önemi araştırılmıştır. Anketler ve firmalardan toplanan bilgiler aracılığı ile elde edilen veriler Tablo 2'de gösterilmiştir.

Potansiyel bir beton pompası alıcısı, tercihini aşağıdaki faktörlere göre yapabilmektedir:

- Düşük fiyat ve işletme maliyeti,

- Yüksek pompalama hızı,

- Tercih edilen ikinci el alternatifi,

- Düşük maliyetli ve hızlı teknik servis imkânı.

Bu faktörlere ek olarak; makine gücü, boru çap1 ve en uygun maksimum agrega çapı gibi çeşitli teknik özellikler de göz önünde bulundurulabilmektedir. Ancak, anket kapsamında yapılan bire bir görüşmeler neticesinde, bu özelliklerin tercihler üzerinde önemli etkilerinin olmadığ 1 ve maksimum pompalama hızı ölçütü içerisinde temsil edilebilecekleri belirlenmiştir. Türkiye karayollarında belirli bir yasal hız limiti olduğu için beton pompasının maksimum hız kapasitesi de bu çalışmada göz önüne alınmamıştır.

Tablo 2. Ölçütlerin değerleri

\begin{tabular}{lccc}
\hline Seçenekler & B1 & B2 & B3 \\
\hline Nicel Ölçütler & & & \\
\hline Satıs fiyatı $(1000 €)$ & 400 & 390 & 300 \\
Günlük işletme maliyeti $(\$)$ & 416 & 384 & 480 \\
En yüksek pompalama hızı $\left(\mathrm{m}^{3} / \mathrm{s}\right)$ & 179 & 163 & 200 \\
\hline Nitel Ölçütler & & & \\
\hline İkinci el & 65.7 & 89.1 & 80.3 \\
Teknik servis & 90.0 & 78.2 & 81.4 \\
\hline
\end{tabular}

\section{Hesaplamalar}

-1. Adım: Hesaplamaların ilk adımında, yapılan anketler sonucunda elde edilen puanlama değerleri Zadeh'in (1975) ortaya attığı dilsel ifadeler türünden tanımlanmıştır. Buna göre, nitel veriler için, Şekil 2'de yer alan üyelik fonksiyonları ölçeği kullanılarak; çok iyi, iyi, orta, kötü ve çok kötü cevaplarının sınırları belirlenmiştir.

Örneğin; ikinci el puanı 65,7 olan B1 alternatifi, ölçekte "orta" değerine denk gelir ve alt sınırı 
50 ve üst sınırı $80^{\prime}$ dir. Bu sınırlar daha sonra $\alpha$ kesim kümelerinin sınırları olarak hesaplamalara dâhil edilmişlerdir.

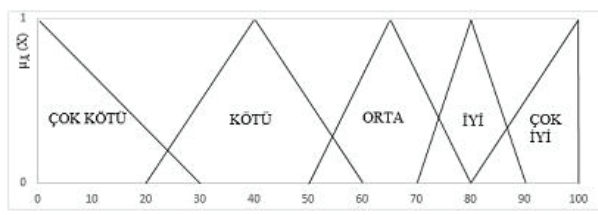

Şekil 2. Nitel veriler için üyelik fonksiyonları
-2. Adım: Tablo 3'te, çalışma kapsamında elde edilen veriler bulanık ve normal sayılar halinde yer almaktadırlar. Çıktı olarak belirlenen "satış fiyatı" verisi değerlendirilerek, yapılan hesaplamalar ile çıtı ve girdilerin alt ve üst sınırları bu adımda belirlenmiştir.

Tablo 3. Ölçütlerin normal ve bulanık sayı türünden değerleri

\begin{tabular}{|c|c|c|c|c|c|c|c|c|c|}
\hline \multirow{3}{*}{ KVB } & \multicolumn{8}{|c|}{ Girdiler $\left(v_{i}\right)$} & \multirow{3}{*}{$\begin{array}{c}\text { Çıtı }(u) \\
\text { Satış } \\
\text { Fiyatı } \\
(1000 €)\end{array}$} \\
\hline & \multicolumn{3}{|c|}{ İkinci El } & \multicolumn{3}{|c|}{ Teknik Servis } & \multirow[t]{2}{*}{ İşletme Maliyeti (\$) } & En Yüksek & \\
\hline & & & & & & & & & \\
\hline & $l$ & $m$ & $u$ & $l$ & $m$ & $u$ & & & \\
\hline B1 & 50 & 65 & 80 & 80 & 90 & 100 & 416 & 179 & 400 \\
\hline B2 & 80 & 85 & 90 & 70 & 75 & 80 & 384 & 163 & 390 \\
\hline B3 & 80 & 85 & 90 & 80 & 85 & 90 & 480 & 200 & 300 \\
\hline
\end{tabular}

Amaç fonksiyonu:

$\max u$

Kisitlar:

$(15 \alpha+50) v_{1} \leq x_{11} \leq(80-15 \alpha) v_{1}$

$(5 \alpha+80) v_{1} \leq x_{12} \leq(90-5 \alpha) v_{1}$

$(5 \alpha+80) v_{1} \leq x_{13} \leq(90-5 \alpha) v_{1}$

$(10 \alpha+80) v_{2} \leq x_{21} \leq(100-10 \alpha) v_{2}$

$(5 \alpha+70) v_{2} \leq x_{22} \leq(80-5 \alpha) v_{2}$

$(5 \alpha+80) v_{2} \leq x_{23} \leq(90-5 \alpha) v_{2}$
$416 \times v_{3}=x_{31}, 384 \times v_{3}=x_{32}, 480 \times v_{3}=x_{33}$

$179 \times v_{4}=x_{41}, 163 \times v_{4}=x_{42}, 200 \times v_{4}=x_{43}$

$400 \times u=y_{11}, 390 \times u=y_{12}, 300 \times u=y_{13}$

$v_{1}, v_{2}, v_{3}, v_{4}, u \leq \varepsilon$

$u$ değeri, farklı $\alpha$ değerleri için hesaplandıktan sonra tüm aşamalar $v_{1}, v_{2}, v_{3}, v_{4}$ değerleri için tekrarlandığında elde edilen sonuçlar Tablo 4 'te gösterilmiştir.

Tablo 4. Çıktı ve girdilerin alt ve üst sınır değerleri

\begin{tabular}{llllll}
\hline & $\alpha=0$ & $\alpha=0.25$ & $\alpha=0.50$ & $\alpha=0.75$ & $\alpha=1$ \\
\hline$u$ & 0.0025 & 0.0025 & 0.0025 & 0.002461666 & 0.002373208 \\
$v_{1}$ & 0.0125 & 0.01225148 & 0.01206576 & 0.01188441 & 0.01171071 \\
$v_{2}$ & 0.0125 & 0.01207403 & 0.01171865 & 0.01138257 & 0.01106711 \\
$v_{3}$ & 0.002083333 & 0.002078802 & 0.002078771 & 0.002078535 & 0.002078708 \\
$v_{4}$ & 0.005 & 0.004980725 & 0.00498065 & 0.004980575 & 0.0049805 \\
\hline
\end{tabular}

-3. Adım: Hesaplanan ağırlıkların sapma oranları eşit kabul edilerek bir ortak ağırlık edilmiştir. Yapılan hesaplamalar sonucunda elde edilen veriler Tablo 5'te gösterilmiştir. 
Kisitlar:

$$
\begin{aligned}
& -x_{11}-x_{21}-x_{31}-x_{41}+y_{1} \leq 0 \\
& -x_{12}-x_{22}-x_{32}-x_{42}+y_{2} \leq 0 \\
& -x_{13}-x_{23}-x_{33}-x_{43}+y_{3} \leq 0 \\
& -x_{11}+50 \times v_{1} \leq 0,-x_{11}+80 \times v_{1} \leq 0 \\
& -x_{12}+80 \times v_{1} \leq 0,-x_{12}+90 \times v_{1} \leq 0 \\
& -x_{13}+80 \times v_{1} \leq 0,-x_{13}+90 \times v_{1} \leq 0 \\
& -x_{21}+80 \times v_{2} \leq 0,-x_{21}+100 \times v_{2} \leq 0 \\
& -x_{21}+80 \times v_{2} \leq 0,-x_{21}+100 \times v_{2} \leq 0 \\
& -x_{21}+80 \times v_{2} \leq 0,-x_{21}+100 \times v_{2} \leq 0 \\
& -x_{22}+70 \times v_{2} \leq 0,-x_{22}+80 \times v_{2} \leq 0 \\
& -x_{23}+80 \times v_{2} \leq 0,-x_{23}+90 \times v_{2} \leq 0 \\
& -x_{31}+416 \times v_{3} \leq 0,-x_{41}+179 \times v_{4} \leq 0
\end{aligned}
$$

$$
\begin{aligned}
& -x_{32}+384 \times v_{3} \leq 0,-x_{42}+163 \times v_{4} \leq 0 \\
& -x_{33}+480 \times v_{3} \leq 0,-x_{43}+200 \times v_{4} \leq 0 \\
& -y_{1}+400 \times u \leq 0 \\
& -y_{2}+390 \times u \leq 0 \\
& -y_{3}+300 \times u \leq 0 \\
& -u+u^{*} \times \varphi \leq 0, u+u^{*} \times \varphi \leq u^{*} \\
& -v_{1}+v_{1}^{*} \times \varphi \leq 0, v_{1}+v_{1}^{*} \times \varphi \leq v_{1}^{*} \\
& -v_{2}+v_{2}^{*} \times \varphi \leq 0, v_{2}+v_{2}^{*} \times \varphi \leq v_{2}^{*} \\
& -v_{3}+v_{3}^{*} \times \varphi \leq 0, v_{3}+v_{3}^{*} \times \varphi \leq v_{3}^{*} \\
& -v_{4}+v_{4}^{*} \times \varphi \leq 0, v_{4}+v_{4}^{*} \times \varphi \leq v_{4}^{*} \\
& v_{1}, v_{2}, v_{3}, v_{4}, u \leq \varepsilon
\end{aligned}
$$

Tablo 5. Çıktı ve girdilerin ortak ağırlık kümesi

\begin{tabular}{llllll}
\hline & $\boldsymbol{\alpha}=\mathbf{0}$ & $\boldsymbol{\alpha}=\mathbf{0 . 2 5}$ & $\boldsymbol{\alpha}=\mathbf{0 . 5 0}$ & $\boldsymbol{\alpha}=\mathbf{0 . 7 5}$ & $\boldsymbol{\alpha}=\mathbf{1}$ \\
\hline $\boldsymbol{u}^{*}$ & 0.00125 & 0.00125 & 0.00125 & 0.00123085 & 0.0001187129 \\
$\boldsymbol{v}_{\mathbf{1}}^{*}$ & 0.00625 & 0.00612574 & 0.00603288 & 0.00594228 & 0.005852767 \\
$\boldsymbol{v}_{\mathbf{2}}^{*}$ & 0.00625 & 0.006037015 & 0.005859325 & 0.00569121 & 0.005531439 \\
$\boldsymbol{v}_{\mathbf{3}}^{*}$ & 0.001041666 & 0.001039401 & 0.001039385 & 0.00103925 & 0.001039913 \\
$\boldsymbol{v}_{\mathbf{4}}^{*}$ & 0.0025 & 0.002490362 & 0.002490325 & 0.00249026 & 0.002489149 \\
\hline
\end{tabular}

-4. Adım: KVB'lerin bulanık etkinlik değerleri her bir $\alpha$ değeri için hesaplanırken (25), (26), (27) ve (28) numaraları eşitliklerden faydalanılmıştır. Örneğin; $\alpha=0$ için B1 kodlu beton pompasının $m$ değerini hesaplarken yapılan işlemler aşağıda açıklanmıştır.

$\alpha=0$ için,

$$
\begin{aligned}
& \left(e_{B 1}^{m}\right)_{0}=\frac{u^{*} \times y_{11}^{m}}{v_{1}^{*} x_{11}^{m}+v_{2}^{*} x_{21}^{m}+v_{3} x_{31}^{m}+v_{4}^{*} x_{41}^{m}} \\
& \left(e_{B 1}^{m}\right)_{0}=\frac{0.00125 \times 400}{(0.00625 \times 65)+(0.00625 \times 90)+\left(0.001041666^{*} 416\right)+(0.0025 \times 179)} \\
& \left(e_{B 1}^{m}\right)_{0}=0.270331196
\end{aligned}
$$

Çalışma kapsamında değerlendirmeye alınan tüm beton pompası alternatiflerinin sonuçları, diğer $\alpha$ değerleri için aynı şekilde hesaplanmış ve elde edilen sonuçlar Tablo 6'da toplu olarak verilmiştir.
Tablo 6'da yer alan sonuçlara göre, tüm KVB'lerin etkinlik değerlerinin 1'den küçük olması nedeniyle ölçeklendirme işlemi yapılmıştır. Bu işlem için (29) numaralı eşitlik kullanılmıştır.

Birinci KVB'nin $\alpha=0$ durumu için;

$$
\left(U_{B 1}^{*}\right)_{0}=\frac{0.00125}{0.2840335}=0.004400889
$$

Buradan, girdilerin ölçeklendirilmiş ağırlıklarında bir değişiklik yapılmadığı anlaşılmaktadır. Bu durumda, ölçeklendirilmiş çıktı ağırlıkları her bir KVB için Tablo 7'de gösterilmiştir. 
Bulanı veri zarflama analizi ile beton pompası seçimi

Tablo 6. KVB etkinlik değerleri

\begin{tabular}{lccccc}
\hline $\begin{array}{l}\text { KVB } \\
\text { Etkinlik } \\
\text { Değeri }\end{array}$ & $\alpha=0$ & $\alpha=0,25$ & $\alpha=0,5$ & $\alpha=0,75$ & $\alpha=1$ \\
\hline$e_{B 1}^{l}$ & 0.226076444 & 0.229979335 & 0.234165702 & 0.234247848 & 0.228294199 \\
$e_{B 1}^{m}$ & 0.24693734 & 0.250981784 & 0.255342551 & 0.255230237 & 0.248549899 \\
$e_{B 1}^{u}$ & 0.267798236 & 0.271984234 & 0.276519401 & 0.276212626 & 0.268805599 \\
\hline$e_{B 2}^{l}$ & 0.267060229 & 0.271497402 & 0.276273844 & 0.2762135 & 0.269049927 \\
$e_{B 2}^{m}$ & 0.276625425 & 0.281110064 & 0.285949445 & 0.285784336 & 0.278275094 \\
$e_{B 2}^{u}$ & 0.28619062 & 0.290722727 & 0.295625047 & 0.295355171 & 0.287500262 \\
\hline$e_{B 3}^{l}$ & 0.216995325 & 0.220445933 & 0.224177973 & 0.223986637 & 0.21804048 \\
$e_{B 3}^{m}$ & 0.22377643 & 0.227251537 & 0.231019597 & 0.230745962 & 0.22454785 \\
$e_{B 3}^{u}$ & 0.230557535 & 0.23405714 & 0.237861221 & 0.237505287 & 0.231055219 \\
\hline & & & & &
\end{tabular}

Tablo 7. Ölçeklendirilmiş çıktı ağırlıkları

\begin{tabular}{llllll}
\hline$\alpha$ & \multicolumn{1}{c}{0} & \multicolumn{1}{c}{0,25} & \multicolumn{1}{c}{0,5} & \multicolumn{1}{c}{0,75} & \multicolumn{1}{c}{1} \\
\hline$U_{B 1}^{*}$ & 0.004400889 & 0.004332513 & 0.004282618 & 0.004234864 & 0.004189321 \\
$U_{B 2}^{*}$ & 0.004479714 & 0.004409538 & 0.0043584 & 0.004309324 & 0.004262323 \\
$U_{B 3}^{*}$ & 0.006672793 & 0.006572578 & 0.006500188 & 0.006430755 & 0.006364424 \\
\hline
\end{tabular}

Ölçeklendirilmiş ağırlıklar elde edildikten sonra, gösterilmiştir. Bu değerlere göre bir sıralama KVB etkinliklerini hesaplamak için yapılmış yapmak için, her bir KVB için hesaplanan tüm olan işlemler tekrarlanarak, yeni etkinlik bulanık değerlerinin ortalaması alınmıştır. değerleri hesaplanmış ve Tablo 8'de

Tablo 8. Ölçeklendirilmiş ağırlıklar ile hesaplanan bulanık etkinlik değerleri

\begin{tabular}{lccccc}
\hline $\begin{array}{l}\text { KVB } \\
\text { Etkinlik } \\
\text { Değeri }\end{array}$ & $\alpha=0$ & $\alpha=0,25$ & $\alpha=0,5$ & $\alpha=0,75$ & $\alpha=1$ \\
\hline$e_{B 1}^{l}$ & 0.903516281 & 0.904746605 & 0.905896641 & 0.907014684 & 0.908117037 \\
$e_{B 1}^{m}$ & 0.951758141 & 0.952373303 & 0.95294832 & 0.953507342 & 0.954058518 \\
$e_{B 1}^{u}$ & 1 & 1 & 1 & 1 & 1 \\
\hline$e_{B 2}^{l}$ & 0.933155071 & 0.933874236 & 0.934541396 & 0.935192589 & 0.935839122 \\
$e_{B 2}^{m}$ & 0.966577536 & 0.966937118 & 0.967270698 & 0.967596295 & 0.967919561 \\
$e_{B 2}^{u}$ & 1 & 1 & 1 & 1 & 1 \\
\hline$e_{B 3}^{l}$ & 0.941176462 & 0.94185043 & 0.942473818 & 0.943082072 & 0.943686218 \\
$e_{B 3}^{m}$ & 0.970588231 & 0.970925215 & 0.971236909 & 0.971541036 & 0.971843109 \\
$e_{B 3}^{u}$ & 1 & 1 & 1 & 1 & 1 \\
\hline
\end{tabular}

$\mathrm{Bu}$ hesaplamalar ile ulașılan sonuçlar Tablo 9'da yer almaktadır.
Tablo 9. Sonuçlar

\begin{tabular}{lcc}
\hline Siralama & Seçenekler & Etkinlik Değeri \\
\hline 1 & B3 & 0.9712269 \\
2 & B2 & 0.967260241 \\
3 & B1 & 0.952929125 \\
\hline
\end{tabular}




\section{Arslan, S. Ulubeyli}

Elde edilen bu sonuçlara göre, B3 kodlu beton pompasının en yüksek etkinlik değerine sahip olması nedeniyle en uygun alternatif olduğu görülmektedir.

\section{Sonuçlar}

Farklı inşaat makineleri, farklı tercih edilme ölçütlerine sahiptirler. Bu nedenle, farklı makine çeşitleri için tek bir ortak çözüm yöntemi geliştirmek anlamlı gözükmemektedir. Bu çalışmada, belirli bir makinenin seçim problemine yardımc olmak amaciyla bir yöntem ortaya koyarken, sadece teknik bilgileri değil, aynı zamanda kullanıcı görüşlerine de yer vererek daha doğru bir sonuca ulaşılmaya çalıșılmıştır. Karar verme süreçlerinde kullanılan tüm yöntemlerin uygulanmasında belirli kabuller yapılması gerektiğinden, bu tür problemler için en iyi çözüm yöntemi diye bir kavramın söz konusu olması beklenemez. Bundan dolayı, karar vericilerin, elde ettikleri sonuçları değerlendirirken, kullandıkları yöntemlerin bazı kusurlara sahip olduklarının farkında olmaları gerekmektedir. BVZA, farklı tür ve birimlerdeki verilerin, mevcut kisitlarla birlikte değerlendirilmesinde kullanılabilecek oldukça faydalı bir yöntemdir. Bu yöntem ile bir veya birden çok parametre hedeflenerek hesaplamalar yapılabilmekte ve karar verme sürecinde avantaj sağlanabilmektedir.

İnşaat sektöründeki firmalar için en iyi alternatifi belirlemek, işlerin yüksek finansal boyutu dikkate alındığında, her zaman için zor ve risklidir. $\mathrm{Bu}$ risk ve tehlikenin en aza indirilmesi veya mümkün olduğunca ortadan kaldırılması için şirketler öncelikle ihtiyaçlarını tanımlamalı ve sonra bu ihtiyaçlarını karş1layabilecek alternatifleri belirlemelidirler. Söz konusu alternatifler ile ilgili gerekli nitel ve/veya nicel veriler bir araya getirilerek, en uygun çözüm yöntemi vasıtasıyla elde edilen sonuçlara göre karar verme süreci tamamlanmalıdır.

$\mathrm{Bu}$ çalışmada ortaya konulan BVZA yönteminin, elde edilen verilerin türü ve birimi ne olursa olsun karar verme problemlerine yardımcı olabileceği görülmektedir.

$\mathrm{Bu}$ çalışma, gelecekte yapılabilecek potansiyel araştırmalarla genişletilmek veya ilerletilmek istenirse, beton pompalarının, birbirleriyle karşılaştırıldıklarında hangi özellikleri dolayısıyla göreceli olarak daha az etkin oldukları tespit edilebilir. Böylelikle, pazarda stratejik açidan daha rekabetçi bir konuma gelebilmek için ürünlerini hangi yönde geliştirmeleri gerektiği ortaya konulabilir.

\section{Kaynaklar}

Akkoyun Ö. ve Toprak Z.F., (2012). Fuzzy-based quality classification model for natural building stone blocks, Engineering Geology, 133-134, 6675.

Aluclu, I., Dalgic, A. ve Toprak, Z.F., (2008). A fuzzy logic-based model for noise control at industrial workplaces, Applied Ergonomics, 39, 3, 368-378.

Chang, P. T. ve Lee, J. H (2012). A fuzzy DEA and knapsack formulation integrated model for project selection, Computers \& Operations Research, 39, 112-125.

Coelli, T., Rao, D. ve Battese, D. (1998). An introduction to efficiency and productivity analysis, Kluwer Academic Publishers, Boston, Dordrecht, London.

Cook, W. D. ve Green, R. H. (2000). Project prioritization: A resource-constrained data envelopment analysis approach, Socio-Economic Planning Sciences, 34, 85-99.

Cooper, W., Seiford, L. ve Tone, K. (2000). Data envelopment analysis: a comprehensive text with models, applications, references and DEA-solver software, Kluwer Academic Publishers, Boston, Dordrecht, London

El-Mashaleh, M. (2010). Decision to bid or not to bid: a data envelopment analysis approach, Canadian Journal of Civil Engineering, 37, 1, 3744.

El-Mashaleh, M. S, Rababeh, S. M. ve Hyari, H. H. (2010). Utilizing data envelopment analysis to benchmark safety performance of construction contractors, International Journal of Project Management, 28, 61-67.

Guo, P. ve Tanaka, H. (2001). Fuzzy DEA: a perceptual evaluation method, Fuzzy Sets and Systems, 119, 149-160. 


\section{Bulanı veri zarflama analizi ile beton pompası seçimi}

Kao, C. ve Liu, S. T.(200). Data envelopment analysis with missing data: an application to university libraries in Taiwan, The Journal of the Operational Research Society, 51, 8, 897-905.

Ksiazek, M., Nowak, P., Roslon, J., ve Wieczorek, T., (2014). Multicriteria assessment of selected solutions for the building structural walls, Proceedings, XXIII R-S-P seminar, Theoretical Foundation of Civil Engineering, 406 - 411, Wrocław.

Lertworasirikula, S., Fanga, S. C., Joinesb, J. A. ve. Nuttlea, H. L. (2003). Fuzzy data envelopment analysis (DEA): a possibility approach, Fuzzy Sets and Systems, 139, 2, 379-394.

Li, Q., Wang, K., ve Cross, S. (2013) Evaluation of warm mix asphalt (WMA): a case study, Proceedings, Airfield and Highway Pavement Conference, 118-127, Los Angeles.

Meada, Y., Entani, T. ve Tanaka, H. (1998). Fuzzy DEA with interval efficiency, Proceedings of the 6th European Congress on Intelligent Techniques and Soft Computing, 2, 1067-1071, Aachen.

Oruç, K. (2008). Veri zarflama analizi ile bulanik ortamda etkinlik ölçümleri ve üniversitelerde bir uygulama, Doktora Tezi, Süleyman Demirel Üniversitesi Sosyal Bilimler Enstitüsü, Isparta.

Ozbek, M., de la Garza, J. ve Triantis, K. (2010). Efficiency measurement of bridge maintenance using data envelopment analysis, Journal of. Infrastructe System, 16, 1, 31-39.

Saati, S. M. ve Memariani, A., (2005). Reducing weight flexibility in fuzzy DEA, Applied Mathematics and Computation, 161, 611-622.

Saati, S. M., Memariani, A. ve Jahanshahloo, G. R. (2002). Efficiency analysis and ranking of DMUs with fuzzy data, Fuzzy Optimization and Decision Making, 1, 3, 255-267.

Sengupta, K. J. (1992). A fuzzy system approach in data envelopment analysis, Computer Mathematics and Application, 24, 8/9, 259-266.

Tam, C. M., Tong, T. K. L., and Wong, Y. W. (2004). Selection of concrete pump using the superiority and inferiority ranking method, Journal of Construction Engineering and Management, 130, 6, 827-834.

Tatari, O. ve Kucukvar, M. (2012). Eco-Efficiency of construction materials: data envelopment analysis, Journal of Construction Engineering and Management, 138, 6, 733-741.
Taylan, O., Bafail, O. A, Abdulaal, M. S. R. ve Kabli, M. R. (2014). Construction projects selection and risk assessment by fuzzy AHP andfuzzy TOPSIS methodologies, Applied Soft Computing, 17, $105-116$.

Toprak, Z.F., (2009). Flow discharge modeling in open canals using a new fuzzy modeling technique (SMRGT), CLEAN-Soil, Air, Water, 37, 9, 742-752.

Toprak, Z.F. ve Cigizoglu, H.K., (2008). Predicting longitudinal dispersion coefficient in natural streams by artificial intelligence methods, Hydrological Processes, 22, 20, 4106-4129.

Toprak, Z.F. ve Savci, M.E., (2007). Longitudinal dispersion coefficient modeling in natural channels using fuzzy logic, CLEAN-Soil, Air, Water, 35, 6, 626-637.

Toprak, Z.F., Eris, E., Agiralioglu, N., Cigizoglu, H.K., Yilmaz, L., Aksoy, H., Coskun, G., Andic, G. ve Alganci, U., (2009). Modeling monthly mean flow in a poorly gauged basin by fuzzy logic, CLEAN-Soil, Air, Water, 37, 7, 555-564.

Toprak Z.F., Hamidi N, Kisi O, ve Gerger R., (2014). Modeling dimensionless longitudinal dispersion coefficient in natural streams using artificial intelligence methods, KSCE Journal of Civil Engineering March 2014, 18, 2, 718-730.

Torfi, F., Farahani, R. Z., ve Rezapour, S. (2010). Fuzzy AHP to determine the relative weights of evaluation criteria and Fuzzy TOPSIS to rank the alternatives, Applied Soft Computing, 10, 2, 520528.

Ulubeyli, S. and Kazaz, A. (2009). A multiple criteria decision-making approach to the selection of concrete pumps, Journal of Civil Engineering and Management, 15, 4, 369-376.

Wang, C. H., Chuang, C. C. ve Tsai, C. C. (2009). A fuzzy DEA-Neural approach to measuring design service performance in PCM projects, Automation in Construction, 18, $702-713$.

Zadeh, L. (1965), Fuzzy sets, Information and Control, 8, 338-353.

Zadeh, L. (1975), The concept of a linguistic variable and its application to approximate reasoning, Information Sciences, 8, 199-249.

Zhou, Z., Zhao, L , Lui, S. ve Ma, C. (2012). A generalized fuzzy DEA/AR performance assessment model, Mathematical and Computer Modelling, 55, 2117-2128. 


\section{Arslan, S. Ulubeyli}

\section{Concrete pump selection using fuzzy data envelopment analysis}

\section{Extended abstract}

The aim of the study is to evaluate construction machine selection problems in terms of concrete pumps and to assert a method which may help concrete pump users and producers during the utilization and production process. For a decision maker, it is important to reach accurate information and solution in making an appropriate decision. Considering the enormous financial sizes of construction projects, it is clear that unfavourable decisions may cause loss of huge amount of money and time. In the construction industry, decisions are usually made among different alternatives. In this respect, Data Envelopment Analysis (DEA) is an efficient method to evaluate a group of decision making units (DMUs) using multiple inputs to produce multiple outputs with comparative efficiency without knowing production functions. In conventional DEA models, the data used for evaluation are assumed to be classic (crisp) values. However, most of the real cases, it is always not possible to obtain only crisp data. To deal with fuzzy data, Fuzzy DEA (FDEA) method, which determines the relative efficiency by assigning fuzzy weights to DMUs inputs and outputs of which relative efficiencies are maximized, can be used. Separate problems for each DMU allow different weights to be used in computing the relative efficiency of different DMUs. Therefore, a need of common set of weights (CSW), which is done by three steps, occurs. In the first step, an upper bound is determined for inputs and outputs, and then, a CSW is determined in the second step. In the third step, the efficiency score is calculated through these findings. In this study $\alpha$-cuts approach developed by Maeda et al. (1998) and improved by Saati et al. (2002) is used in the selection of concrete pumps.

Concrete pumps were chosen in this study, according to their potential effect on the productivity and the quality of products and services in the construction job-site. Moreover, these machines require a great financial investment. However, since all of solution methods are based on some assumptions, it can be stated that there is no best evaluation technique to deal with selection problems. FDEA is a suitable method to deal with different kinds of data and constraints together and to consider one or more variables during the analysis.

For construction companies, it is difficult and risky to determine the most favourable alternative. In order to overcome this problem, companies should decide their needs, and then, identify their alternatives. According to results obtained from the current case analysis, when considering the selling price as output, B3 was found out to be the most suitable concrete pump, followed by B2 and B1, respectively.

For potential future studies, using FDEA approach companies may find out the less advantageous criterion of their products and take the necessary actions to produce the most preferred products in their field for gaining a competitive advantage in the market.

Keywords: Concrete pump, Construction machines, FDEA, Multi criteria decision making 